\title{
Estrategia innovadora enfocada en parejas del mismo sexo para disminuir la infección del VIH en hombres Latinos
}

\section{A couple-based approach: An innovative effort to tackle HIV infection among Latino gay men}

Omar Martinez (1), Elwin Wu (2), Theo Sandfort (1), Andrew Z. Shultz (1), Jonathan Capote (3), Silvia Chávez (4), Eva Moya (4), Brian Dodge (5), Gabriel Morales, Antonio Porras (6), Hugo Ovejero (7)

(1) HIV Center for Clinical and Behavioral Studies at the New York State Psychiatric Institute and Columbia University

(2) School of Social Work at Columbia University

(3) Communications and Development Assistant at AID for AIDS International

(4) University of Texas-El Paso

(5) Indiana University-Bloomington

(6) Immigration Focus Groups (IFG)

(7) Latino Commission on AIDS

Abstract: The HIV epidemic is a serious and pervasive health issue in the Latino community. While prevention efforts have helped maintain stability in the overall number of infections among Latinos for more than a decade, this population continues to be affected by HIV at high levels. In particular, Predominantly Spanish-speaking Latino men who have sex with men (MSM) are disproportionately impacted by HIV. Several factors contribute to the HIV epidemic among Predominantly Spanish-speaking Latino MSM including substance use; intimate partner violence; the presence of certain STIs; samesex relationship dynamics; avoidance of seeking testing counseling and treatment out of fear of discrimination and immigration status; and poverty, migration patterns, and language barriers. In particular, epidemiological behavioral research has identified how relationship dynamics in male couples are associated with sexual risk behavior. Consequently, further research is needed to identify and deliver interventions geared toward couple-based risk reduction among men in same-sex relationships. This paper describes the potential significance that innovative couple-based approaches can have on reducing HIV and AIDS cases among Predominantly Spanish-speaking Latino MSM and their same-sex partners.

Keywords: HIV prevention, STIs, Predominantly Spanish-speaking Latino MSM, Couple-based intervention, Latino Gay Couples. 
Resumen: EI VIH es un problema de salud importante dentro de la comunidad latina de los Estados Unidos. Gracias a los esfuerzos de prevención, los niveles de contagio entre los latinos se han mantenido estables por más de una década. Sin embargo, esta población sigue siendo afectada a niveles muy altos, en particular entre hombres que tienen sexo con hombres (HSH), de origen latino y que hablan principalmente el idioma español. Existen varios factores que contribuyen a la transmisión del VIH entre esta población, como son: el uso de drogas; la violencia dentro de la pareja; la presencia de infecciones de transmisión sexual; relaciones sexuales sin protección, dentro y fuera de la pareja; el evadir la búsqueda de recursos (prueba y tratamiento adecuado) por temor a ser discriminado o por su estatus migratorio; la escasez de recursos económicos o estado de pobreza y los patrones relacionados a la migración. En particular, Investigaciones Epidemiológicas de Comportamientos han determinado: cómo algunas dinámicas en parejas están directamente asociadas a los comportamientos sexuales de riesgos. En consecuencia, es necesaria mayor investigación para identificar esas dinámicas, y a su vez, realizar intervenciones dirigidas a la reducción de conductas de riesgo enfocadas en parejas de hombres del mismo sexo. En este escrito, se describe la importancia del uso de las relaciones de pareja como estrategia en la reducción de la trasmisión del VIH/SIDA en HSH de origen latino y que hablan principalmente el idioma español en los Estados Unidos.

Palabras claves: Prevención del VIH, ETS, Intervenciones con enfoque en parejas, Parejas de HSH de origen latino.

Recibido: 20/09/2013 Revisado: 08/11/2013 Aceptado 28/11/2013 Publicado 30/01/2014

Referencia normalizada: (2014). Martinez, O., Wu, E., Sandfort, T., Shultz, A. Z., Chapote, J., Chavez, S., Moya, E., Dodge, B., Morales, G., Porras, A., Ovejero, H. A couple-based approach: An innovative effort to tackle HIV infection among latino gay men. Ehquidad International Welfare Policies and Social Work Journal, 1, 15 - 32 . doi. 10.15257/ehquidad.2014.0001.

Correspondencia: Omar Martinez, J.D., M.P.H.Postdoctoral Research Fellow HIV Center for Clinical and Behavioral Studies at the New York State Psychiatric. Institute and Columbia University. Social Intervention Group at Columbia University School of Social Work. Regular mail: 1051 Riverside Drive, Unit 15. Fedex: 722 West.168th St., Room 316. New York, NY 10032. voice +1(212) 543-5087. fax +1(212) 543-6003. http://www.hivcenternyc.org/index.html; $\quad$ http://www.columbia.edu/cu/ssw/sig/what.html. om2222@columbia.edu. Elwin Wu, PhD. Assistant Professor, School of Social Work at Columbia University ew157@columbia.edu. Theo Sandfort, PhD. Professor, HIV Center at Columbia University tgs2001@columbia.edu. Zach Shultz, MA. Communications and Development Assistant. AID for AIDS International zach.shultz@gmail.com. Silvia Chavez Baray, PhD. Lecturer.University of Texas-El Paso. smchavezbaray@utep.edu. Eva Moya, PhD, LMSW. Assistant Professor, University of Texas-EI Paso. emmoya@utep.edu. Brian Dodge, PhD. Associate Professor, Indiana University-Bloomington. bmdodge@indiana.edu. Gabriel Morales, MPA.Community Activist. gmoralesusc@gmail.com. Antonio Porras, MBA. Community Activist. antonioporrasg@gmail.com. Hugo Ovejero, JD. Community Activist. hovejero@gmail.com. 


\section{INTRODUCTION: HIV AND STIS AMONG LATINO MSM}

According to the most recent CDC data, in 2011, Latinos in the US represented $21 \%$ of new HIV infections $(10,159)$ while representing approximately $16 \%$ of the total US population. For HIV infected Latino men, the most common modes of transmission are male-to-male sexual contact and injection drug use (Centers for Disease Control and Prevention, 2013a; Tung, 2012). Latino men who have sex with men (MSM) are especially impacted, representing $72 \%(7,266)$ of all new HIV infections among Latinos (Kann et al., 2012). Among Latino MSM, $45 \%$ of new infections occurred in those under age 30. Puerto Rican MSM have a substantially higher percentage of diagnosed HIV infections attributed to injection drug use than Latino men born in other countries (Colón-López et al., 2011; Finlinson, Colón, Robles, \& Soto, 2006).

The CDC's newest estimates show that there are about 20 million new sexually transmitted infections (STIs) in the United States each year, costing the American healthcare system nearly $\$ 16$ billion in direct medical costs alone (Centers for Disease Control and Prevention, 2013b). In particular, MSM are disproportionately impacted by STIs. Trend data available for the first time show that MSM now account for nearly three quarters (72 \%) of all primary and secondary syphilis cases. Surveillance data from several major cities throughout the country indicate that an average of 4 in 10 MSM with syphilis are also infected with HIV (Centers for Disease Control and Prevention, 2013c). Rates of reported sexually transmitted infections (STIs) are higher among Latinos than among non-Latino whites (Centers for Disease Control and Prevention, 2007, 2013b). 


\section{KEY FACTORS CONTRIBUTING TO THE PERSISTENT HIGH LEVEL OF HIV} AMONG LATINO MSM

Epidemiological data highlight factors that contribute to HIV risk behavior among Latino MSM. Alcohol and drug use and addiction have been inextricably linked with HIVIAIDS among Latino MSM (Diaz, 2000; Dolezal, Carballo-Diéguez, Nieves-Rosa, \& Díaz, 2000; Mizuno, Borkowf, Ayala, Carballo-Diéguez, \& Millett, 2013). For example, a recent study found an increase in alcohol and substance use among recently-arrived behaviorally bisexual Latino men in the Midwestern United States (Martinez et al., 2012; Martinez et al., 2011). In addition, a venue-based sample study of Latino MSM found that drug use in the previous 6 months ranged from approximately $40 \%$ in New York City and Los Angeles to $16 \%$ in Miami. The most commonly used drugs were marijuana, poppers, cocaine, and methamphetamine (Rafael M. Diaz \& et al., 1999). Another study with an internet-based sample of Latino MSM found that $49 \%$ of the respondents used club drugs (e.g., cocaine, crystal methamphetamines, ketamine, volatile nitrites) in the past 6 months, with poppers being the most popular (32\%) (Fernandez et al., 2005).

In addition to alcohol and drug abuse, domestic violence greatly impacts Latino MSM. In particular, domestic violence has been linked to HIV risk among Latino MSM (Williams, Wyatt, Resell, Peterson, \& Asuan-O'Brien, 2004). The National Coalition of Anti-Violence Programs reported that nationwide in 2008, approximately $24 \%$ of domestic violence complaints made by members of the LGBT community were made by recent immigrants. Latinos made up the second largest group with reports following survivors of African-descent. It was estimated that most of these cases were among couples, either in casual or long-term relationships (National Coalition of AntiViolence, 2008). Another study conducted among Puerto Rican gay men concluded that close to half of the participants experienced some sort of violence in their intimate relationships and sexual coercion and violence that was linked to HIV transmission (Madera \& Toro-Alfonso, 2005). However, 
more research is needed to further understand the impact of intimate-partner violence and HIV risk among Latino MSM.

Research shows that as many as two-thirds of new HIV infections occur among gay men in committed relationships, which points to the dynamics of relationships as factors associated with sexual risk behaviors (Sullivan, Salazar, Buchbinder, \& Sanchez, 2009). Therefore, relationship status stands out as an important context for understating HIV among Latino gay men (Beougher, Gomez, \& Hoff, 2011). A study conducted at Emory University found that a significant number of men in longer-term relationships are unaware of their partner's HIV status (Sullivan et al., 2009). In fact, many gay men in relationships believe that they are at less risk for HIV and are therefore less likely to have been recently tested for HIV (Sullivan et al., 2009; Wu, ElBassel, Donald McVinney, Fontaine, \& Hess, 2010). Previous research shows between $40-60 \%$ of Latino gay men have primary partners (Rafael M. Diaz \& Ayala, 1999; Jarama, Kennamer, Poppen, Hendricks, \& Bradford, 2005; Ramirez-Valles, Garcia, \& Campbell, 2008) and that being in a relationship increases the rate or is predictive of unprotected anal intercourse with a primary partner (Diaz, Stall, Hoff, Daigle, \& Coates, 1996). However, more research is needed to explore how relationship dynamics are associated with sexual risk behavior. There is also an urgent need to develop culturally and linguistically congruent interventions and programs to address these concerns.

Behavioral data also suggest that Predominantly Spanish-speaking Latinos are disproportionately at risk for HIV compared to their English-speaking Latino and non-Latino counterparts (Rhodes et al., 2010; Wohl, Tejero, \& Frye, 2009; Wolff \& Ellis, 2009). Predominantly Spanish-speaking Latino men are less likely to report: using a condom at most recent intercourse; seeking or accessing health services; and having a personal doctor and health insurance when compared to English-speaking Latino men or non-Latino men (North Carolina Department of Health and Human Services, 2004; North Carolina 
Institute of Medicine, 2003). In addition, research suggests that less acculturated Latinos are more likely to engage in risk behaviors because of pre-and-post migration experiences including discrimination, stigma and isolation (Hines \& Caetano, 1998; Marsiglia \& Navarro, 1999).

\section{ADVANCING NOVEL HIV PREVENTION INTERVENTIONS WITH} PREDOMINANTLY SPANISH-SPEAKING LATINO MSM THROUGH THE LENS OF COUPLE-BASED APPROACHES

The U.S. National Institute of Mental Health (NIMH) and the Centers for Disease Control and Prevention (CDC) launched a call to maximize: (1) healthy sex interventions, (2) community and structural interventions, (3) integrated biomedical and behavioral interventions, and (4) interventions to improve uptake of HIV testing. The NIMH and CDC also highlighted the need to address research gaps in designing risk-reducing and sexual healthpromoting interventions for MSM, including intervention to address mental health, substance use, HIV disclosure, and stigma (Grossman et al., 2011; Kuehn, 2011).

Focusing on one area of innovation - a couple-based HIVISTI prevention - is an approach that warrants further expansion, taking into consideration the call from the NIMH and the CDC and given: (1) the substantial evidence indicating that condom use among MSM is less likely with partners in more established relationships compared to "casual" partners (Adib, Joseph, Ostrow, \& James, 1991; Berger, 1990; Bosga et al., 1995; Chng \& GeligaVargas, 2000; Dawson et al., 1994; R. M. Diaz et al., 1996; Doll et al., 1991; Elford, Bolding, Maguire, \& Sherr, 1999; Fitzpatrick, McLean, Dawson, Boulton, \& Hart, 1990; R.B. Hays, Kegeles, \& Coates, 1990; R. B. Hays, Kegeles, \& Coates, 1997; Hoff, Coates, Barrett, Collette, \& Ekstrand, 1996; Koblin et al., 2003; McKusick, Horstman, \& Coates, 1985; Misovich, Fisher, \& Fisher, 1997; Myers et al., 1999; Myers et al., 1992; Piaseczna et al., 2001; Valdiserri et al., 1988; Wagner, Remien, \& Carballo-Dieguez, 1998); (2) the limited research to address the growing health needs of Predominantly 
Spanish-speaking Latino MSM (Bedoya et al., 2012; Martinez et al., 2012; Martinez et al., 2011) and drug users (Bedoya et al., 2012; Díaz, Heckert, \& Sánchez, 2005; Rhodes et al., 2012); and (3) the lack of couple-based interventions for MSM identified in meta-analyses and systematic reviews of HIV prevention intervention trials with stronger scientific design (Johnson et al., 2002; Johnson et al., 2005; Manhart \& Holmes, 2005; Semaan et al., 2002).

There is evidence consistent with the view that a couple-based approach can be effective in promoting sexual risk reduction among populations at elevated risk for HIV (Hoebbel \& Fals-Stewart, 2003; Stappenbeck, Hoebbel, \& FalsStewart, 2004). A meta-analysis of 66 studies on the efficacy of HIV counseling and testing revealed that mixed HIV serostatus couples who received joint HIV counseling and testing had substantial improvement in condom use, whereas those counseled individually showed scant improvement following HIV counseling and testing (Higgins et al., 1991). Another study found that married or cohabiting drug-abusing men who were assigned to 12-session couples risk reduction intervention reported significantly fewer sexual risk behaviors and a higher proportion of HIV testing compared to married or cohabiting drug abusing men who were assigned to a traditional 12-session individually-based substance abuse counseling and HIV education intervention (Hoebbel \& Fals-Stewart, 2003; Stappenbeck et al., 2004). The Social Intervention Group (SIG) at Columbia University has demonstrated that Connect is efficacious in reducing sexual risk behavior among mixed-gender couples at 3-months and 12-month time points following receipt of the intervention (El-Bassel et al., 2003, 2005). While the literature reviewed here indicates substantial promise within the burgeoning body of evidence supporting couple-based HIVISTI prevention, the focus has been almost exclusively on mixed gender couples.

It is also important to note that while MSM account for the majority of HIV cases in the U.S., the number of rigorously-tested behavioral risk reduction interventions - a crucial component of the public health response to HIV given 
the absence of a vaccine or cure-is lowest for MSM compared to other populations (Johnson et al., 2002; Semaan et al., 2002). Furthermore, only a few interventions in the DEBI Project target MSM, and none target Predominantly Spanish-speaking Latino MSM or Latino gay couples. As such, a need exists to develop a couple-based HIVISTI preventive intervention that is culturally and linguistically appropriate and contextually tailored for Predominantly Spanish-speaking Latino MSM in same-sex relationships.

Our community-based research team has proposed the adaptation of "Connect 'n Unite" (CNU), a 4-session couple-based HIV preventive intervention for stimulant-using Black MSM in same-sex relationships, to reduce the disproportionate HIV burden borne by Latino MSM. In particular, relying on current epidemiological and ethnographic research that points to an increasing proportion of HIV and AIDS cases among Predominantly Spanish-speaking Latino MSM and men in long-term same-sex relationships, we adapted the intervention to target both of these areas simultaneously by recruiting Predominantly Spanish-speaking Latino MSM and their same-sex partners.

$C N U$ sessions cover several topics including self-care (e.g., information about HIVIAIDS, stimulant use, self-care plan); communication (e.g., use of effective communication styles); relationship strengthening (e.g., identification of unwritten rules and sexual decision-making); and couple problem solving (e.g., identification of a support mechanism for each partner). The intervention was found effective in increasing condom use and HIV testing and decreasing harmful substance use among Black male couples (Wu et al., 2010).

Given the high rates of HIV among Latino MSM and the social forces and structures that impact the health of Latino MSM, the potential intervention should cover several components including HIV and STI information; the impact of migration-related changes and lack of Spanish-language prevention campaigns; limited access to health services; and risk reduction strategies 
with a focus on sexual behaviors and illicit drug use. In particular, migration has emerged as a risk factor for HIVIAIDS in the United States. These particular components should be guided by theories that have previously been used for reducing risk behaviors and illicit drug use, including social cognitive theory (SCT) (Bandura, 1986) and a relationship-oriented ecological framework (Bronfenbrenner, 1977), both of which have also informed previous evidence-based interventions for couples, including $C N U$. SCT is the most frequently used theoretical basis for HIV prevention interventions trials in the U.S. (Semaan et al., 2002), and SCT-based interventions result in clinically significant risk reduction (Kalichman, Carey, \& Johnson, 1996). The central tenets of SCT utilized by the original and revised Connect interventions are self-efficacy and outcome expectancies. A relationshiporiented ecological perspective informs a couple-based, multi-level approach to sexual risk reduction by focusing on different levels of key individual, relational and contextual factors that play a role in initiating and maintaining protective behaviors among intimate partners.

A couple-based intervention for Predominantly Spanish-speaking Latino MSM and their same-sex partners should also incorporate components that address issues surrounding domestic violence. Preliminary research indicates that domestic violence is extremely high among Predominantly Spanish-speaking Latino MSM and leads to other sets of health concerns, including mental health issues such as depression and anxiety and risky sexual behaviors. Domestic violence needs to be addressed by emphasizing empowerment approaches, building social networks, and referring individuals to domestic violence resources. In addition, the intervention should take into consideration the diversity of the Latino population in the US, lived experiences of Latino MSM, and migration experiences of Latinos as a factor shaping sexual behaviors.

All of the potential components of the intervention, including HIV and STI information, access to health services, and harm-reduction skills should be 
evaluated, examined, and revised to develop an effective HIV prevention intervention for the targeted population. Given the limited research related to Latino gay couples as a context, and in particular, among Predominantly Spanish-speaking Latino MSM in same-sex relationships, a needs assessment should also be conducted to further understand the issues affecting this community. These findings should then inform the development of the intervention.

The adapted $C N U$ intervention for Predominantly Spanish-speaking Latino MSM should contain elements that effective HIV prevention interventions share, including (1) having a solid theoretical foundation, (2) offering multiple sessions, (3) setting goals and discussions discussions on condom use and testing, as exemplified with adapted and refined key activities, including homework assignments, (4) increasing awareness, knowledge, and positive attitudes and beliefs about risk reduction, (5) increasing risk reduction norms and social support for protection, (6) providing positive reinforcement for healthy individual and couple-based behavioral change, and (7) providing guidance on how to utilize available services. It will also need to incorporate, through an adaptation and refinement process, perspectives from service providers. The potential adapted intervention will not only benefit Latino MSM, their same-sex partners and communities, but will also help inform future research and intervention strategies for other vulnerable populations.

\section{ACKNOWLEDGMENTS}

Mr. Martinez is supported by a NIMH training grant (T32-MH19139 Behavioral Sciences Research in HIV Infection; Principal Investigator: Theo Sandfort, Ph.D.) at the HIV Center for Clinical and Behavioral Studies (P30-MH43520; Center Director: Robert H. Remien, Ph.D.). 


\section{REFERENCES}

Adib, S. M., Joseph, J. G., Ostrow, D. G., \& James, S. A. (1991). Predictors of relapse in sexual practices among homosexual men. AIDS Education \& Prevention, 3(4), 293-304.

Bandura, A. (1986). Social foundations of thought and action: A social and cognitive theory. Englewood Cliffs, NJ: Prentice-Hall.

Bedoya, C. A., Mimiaga, M. J., Beauchamp, G., Donnell, D., Mayer, K. H., \& Safren, S. A. (2012). Predictors of HIV transmission risk behavior and seroconversion among Latino men who have sex with men in Project EXPLORE. AIDS and Behavior, 16 (3), 608-617. doi: 10.1007/s10461-0119911-4

Beougher, S. C., Gomez, W., \& Hoff, C. C. (2011). The couple as context: Latino gay male couples and HIV (English). Culture, health \& sexuality, 13 (3), 299-312.

Berger, R. M. (1990). Men together: Understanding the gay couple. Journal of Homosexuality, 19 (3), 31-49.

Bosga, M. B., de Wit, J. B., de Vroome, E. M., Houweling, H., Schop, W., \& Sandfort, T. G. (1995). Differences in perception of risk for HIV infection with steady and non-steady partners among homosexual men. AIDS Education \& Prevention, 7 (2), 103-115.

Bronfenbrenner, U. (1977). Toward an experimental ecology of human development. American Psychologist, 37 (7), 513-531.

Centers for Disease Control and Prevention. (2007). Sexually Transmitted Disease Surveillance, 2006. Atlanta, GA: U.S. Department of Health and Human Services.

Centers for Disease Control and Prevention. (2013a). Diagnoses of HIV Infection in the United States and Dependent Areas, 2011. Atlanta, GA: Department of Health and Human Services, Centers for Disease Control and Prevention.

Centers for Disease Control and Prevention. (2013b). Incidence, Prevalence, and Cost of Sexually Transmitted Infections in the United States. Atlanta, 
GA: Department of Health and Human Services, Centers for Disease Control and Prevention.

Centers for Disease Control and Prevention. (2013c). STD Trends in the United States Atlanta, GA Department of Health and Human Services, Centers for Disease Control and Prevention

Chng, C. L., \& Geliga-Vargas, J. (2000). Ethnic identity, gay identity, sexual sensation seeking and HIV risk taking among multiethnic men who have sex with men. AIDS Education \& Prevention, 12 (4), 326-339.

Colón-López, V., Rodríguez-Díaz, C. E., Ortiz, A. P., Soto-Salgado, M., Suárez, E., \& Pérez, C. M. (2011). HIV-related risk behaviors among a sample of men who have sex with men in Puerto Rico: an overview of substance use and sexual practices. Puerto Rico Health Sciences Journal, 30 (2), 65-68.

Dawson, J. M., Fitzpatrick, R. M., Reeves, G., Boulton, M., McLean, J., Hart, G. J., \& Brookes, M. (1994). Awareness of sexual partners' HIV status as an influence upon high-risk sexual behaviour among gay men. AIDS, 8 (6), 837-841.

Deschamps, M., Pape, J., Haffner, A., Hyppolite, R., \& Johnson, W. (1991). Heterosexual activity in at risk couples for HIV infection. Paper presented at the VII International Conference on AIDS, Florence.

Diaz, R. M. (2000). Drug Use and Risky Sexual Behavior in Latino Gay Men.

Diaz, R. M., \& Ayala, G. (1999). Love, passion and rebellion: ideologies of HIV risk among Latino gay men in the USA. [Article]. Culture, Health \& Sexuality, 1 (3), 277-293. doi: 10.1080/136910599301021

Diaz, R. M., \& et al. (1999). Predictors of sexual risk in Latino gay/bisexual men: the role of demographic, developmental, social cognitive, and behavioral variables. HISPANIC JOURNAL OF BEHAVIORAL SCIENCES, 21 (4), 480-501.

Díaz, R. M., Heckert, A. L., \& Sánchez, J. (2005). Reasons for stimulant use among Latino gay men in San Francisco: a comparison between methamphetamine and cocaine users. Journal Of Urban Health: Bulletin Of The New York Academy Of Medicine, 82 (1 Suppl 1), i71-i78. 
Diaz, R. M., Stall, R. D., Hoff, C., Daigle, D., \& Coates, T. J. (1996). HIV risk among Latino gay men in the southwestern United States. AIDS Education \& Prevention, 8 (5), 415-429.

Dolezal, C., Carballo-Diéguez, A., Nieves-Rosa, L., \& Díaz, F. (2000). Substance use and sexual risk behavior: understanding their association among four ethnic groups of Latino men who have sex with men. Journal Of Substance Abuse, 11 (4), 323-336.

Doll, L. S., Byers, R. H., Bolan, G., Douglas, J. M., Jr., Moss, P. M., Weller, P. D., . . . Harrison, J. S. (1991). Homosexual men who engage in high-risk sexual behavior. A multicenter comparison. Sexually Transmitted Diseases, 18 (3), 170-175.

El-Bassel, N., Witte, S. S., Gilbert, L., Wu, E., Chang, M., Hill, J., \& Steinglass, P. (2003). The efficacy of a relationship-based HIVISTD prevention program for heterosexual couples. American Journal of Public Health, 93 (6), 963-969.

El-Bassel, N., Witte, S. S., Gilbert, L., Wu, E., Chang, M., Hill, J., \& Steinglass, P. (2005). Long-term effects of an HIVISTI sexual risk reduction intervention for heterosexual couples. AIDS \& Behavior, 9 (1), 1-13.

Elford, J., Bolding, G., Maguire, M., \& Sherr, L. (1999). Sexual risk behaviour among gay men in a relationship. AIDS, 13(11), 1407-1411.

Fernández, M. I., Perrino, T., Collazo, J. B., Varga, L. M., Marsh, D., Hernandez, N., . . . Bowen, G. S. (2005). Surfing new territory: club-drug use and risky sex among Hispanic men who have sex with men recruited on the Internet. Journal Of Urban Health: Bulletin Of The New York Academy Of Medicine, 82(1 Suppl 1), i79-i88.

Finlinson, H. A., Colón, H. M., Robles, R. R., \& Soto, M. (2006). Sexual identity formation and AIDS prevention: an exploratory study of non-gay-identified Puerto Rican MSM from working class neighborhoods. AIDS and Behavior, $10(5), 531-539$.

Fitzpatrick, R., McLean, J., Dawson, J., Boulton, M., \& Hart, G. (1990). Factors influencing condom use in a sample of homosexually active men. Genitourinary Medicine, 66 (5), 346-350. 
Grossman, C. I., Forsyth, A., Purcell, D. W., Allison, S., Toledo, C., \& Gordon, C. M. (2011). Advancing Novel HIV Prevention Intervention Research with MSM- Meeting Report. Public Health Reports, 126 (4), 472-479.

Hays, R. B., Kegeles, S. M., \& Coates, T. J. (1990). High HIV risk-taking among young gay men. AIDS, 4 (9), 901-907.

Hays, R. B., Kegeles, S. M., \& Coates, T. J. (1997). Unprotected sex and HIV risk taking among young gay men within boyfriend relationships. AIDS Education \& Prevention, 9 (4), 314-329.

Higgins, D. L., Galavotti, C., O'Reilly, K. R., Schnell, D. J., Moore, M., Rugg, D. L., \& Johnson, R. (1991). Evidence for the effects of HIV antibody counseling and testing on risk behaviors. JAMA, 266 (17), 2419-2429.

Hines, A. M., \& Caetano, R. (1998). Alcohol and AIDS-related sexual behavior among Hispanics: acculturation and gender differences. AIDS Education And Prevention: Official Publication Of The International Society For AIDS Education, 10 (6), 533-547.

Hoebbel, C., \& Fals-Stewart, W. (2003). The effect of behavioral couples therapy on the degree of indirect risk exposure to HIV among wives of substance-abusing men. Paper presented at the 65th Annual Scientific Meeting of the College on Problems of Drug Dependence, Bal Harbour, FL. Hoff, C. C., Coates, T. J., Barrett, D. C., Collette, L., \& Ekstrand, M. (1996). Differences between gay men in primary relationships and single men: Implications for prevention. AIDS Education \& Prevention, 8 (6), 546-559.

Jarama, S. L., Kennamer, J. D., Poppen, P. J., Hendricks, M., \& Bradford, J. (2005). Psychosocial, behavioral, and cultural predictors of sexual risk for HIV infection among Latino men who have sex with men. AIDS \& Behavior, $9(4), 513-523$.

Johnson, W. D., Hedges, L. V., Ramirez, G., Semaan, S., Norman, L. R., Sogolow, E., . . . Diaz, R. M. (2002). HIV prevention research for men who have sex with men: A systematic review and meta-analysis. Journal of Acquired Immune Deficiency Syndromes, 30 Suppl 1, S118-S129.

Johnson, W. D., Holtgrave, D. R., McClellan, W. M., Flanders, W. D., Hill, A. N., \& Goodman, M. (2005). HIV intervention research for men who have sex 
with men: A 7-year update. AIDS Education and Prevention, 17 (6), 568589.

Kalichman, S. C., Carey, M. P., \& Johnson, B. T. (1996). Prevention of sexually transmitted HIV infection: A meta-analytic review of the behavioral outcome literature. Annals of Behavioral Medicine, 18 (1), 6-15.

Kann, L., Lowry, R., Eaton, D., Wechsler, H., Centers for Disease, C., \& Prevention. (2012). Trends in HIV-Related Risk Behaviors among High School Students--United States, 1991-2011. Morbidity and Mortality Weekly Report. Early Release. Volume 61: Centers for Disease Control and Prevention.

Koblin, B. A., Chesney, M. A., Husnik, M. J., Bozeman, S., Celum, C. L., Buchbinder, S., . . . Team, E. S. (2003). High-risk behaviors among men who have sex with men in 6 US cities: Baseline data from the EXPLORE Study. American Journal of Public Health, 93 (6), 926-932.

Kuehn, B. M. (2011). IOM: Data on Health of Lesbian, Gay, Bisexual, and Transgender Persons Needed. [Article]. JAMA: Journal of the American Medical Association, 305 (19), 1950-1951.

Madera, S. R., \& Toro-Alfonso, J. (2005). Description of a Domestic Violence Measure for Puerto Rican Gay Males. [Article]. Journal of Homosexuality, $50(1), 155-173$.

Manhart, L. E., \& Holmes, K. K. (2005). Randomized controlled trials of individual-level, population-level, and multilevel interventions for preventing sexually transmitted infections: what has worked? Journal of Infectious Diseases, 191 Supp/ 1, S7-24.

Marsiglia, F. F., \& Navarro, R. (1999). Acculturation status and HIVIAIDS knowledge and perception of risk among a group of Mexican American middle school students. Journal of HIVIAIDS Prevention \& Education for Adolescents \& Children, 3 (3), 43-61.

Martinez, O., Dodge, B., Goncalves, G., Schnarrs, P. W., Muñoz-Laboy, M., Reece, M., Fortenberry, J. D. (2012). Sexual Behaviors and Experiences Among Behaviorally Bisexual Latino Men in the Midwestern United States: 
Implications for Sexual Health Interventions. [Article]. Journal of Bisexuality, 12 (2), 283-310. doi: 10.1080/15299716.2012.674865

Martinez, O., Dodge, B., Reece, M., Schnarrs, P. W., Rhodes, S. D., Goncalves, G., Fortenberry, J. D. (2011). Sexual health and life experiences: voices from behaviourally bisexual Latino men in the Midwestern USA. [Article]. Culture, Health \& Sexuality 13 (9), 1073-1089. doi: 10.1080/13691058.2011.600461

McKusick, L., Horstman, W., \& Coates, T. J. (1985). AIDS and sexual behavior reported by gay men in San Francisco. American Journal of Public Health, 75 (5), 493-496.

Misovich, S. J., Fisher, J. D., \& Fisher, W. A. (1997). Close relationships and elevated HIV risk behavior: Evidence and possible underlying psychological processe. Review of General Psychology, 1 (1), 72-107.

Mizuno, Y., Borkowf, C. B., Ayala, G., Carballo-Diéguez, A., \& Millett, G. A. (2013). Correlates of Sexual Risk for HIV Among US-Born and ForeignBorn Latino Men Who Have Sex with Men (MSM): An Analysis from the Brothers y Hermanos Study. Journal Of Immigrant And Minority Health / Center For Minority Public Health.

Myers, T., Allman, D., Calzavara, L., Morrison, K., Marchand, R., \& Major, C. (1999). Gay and bisexual men's sexual partnerships and variations in risk behaviour. Canadian Journal of Human Sexuality, 8 (2), 115-126.

Myers, T., Tudiver, F. G., Kurtz, R. G., Jackson, E. A., Orr, K. W., Rowe, C. J., \& Bullock, S. L. (1992). The Talking Sex Project: Descriptions of the study population and correlates of sexual practices at baseline. Canadian Journal of Public Health. Revue Canadienne de Sante Publique, 83 (1), 4752.

National Coalition of Anti-Violence, P. (2008). Anti-lesbian, gay, bisexual and transgender violence in 2008.

North Carolina Department of Health and Human Services. (2004). Racial and ethnic differences in health in North Carolina: 2004 Update (pp. 1-31). Raleigh, NC: North Carolina Department of Health and Human Services.

North Carolina Institute of Medicine. (2003). NC Latino health 2003. Durham, NC: North Carolina Institute of Medicine. 
Piaseczna, M. A., Craib, K. J., Li, K., Chan, K., Weber, A. E., Strathdee, S. A., . .. Hogg, R. S. (2001). Longitudinal patterns of sexual behavior and condom use in a cohort of HIV-negative gay and bisexual men in Vancouver, British Columbia, Canada, 1995-2000. Journal of Acquired Immune Deficiency Syndromes: JAIDS, 28 (2), 187-193.

Ramirez-Valles, J., Garcia, D., \& Campbell, R. T. (2008). HIV Infection, Sexual Risk Behavior, and Substance Use Among Latino Gay and Bisexual Men and Transgender Persons. [Article]. American Journal of Public Health, 98(6), 1036-1042. doi: 10.2105/ajph.2006.102624

Rhodes, S. D., Hergenrather, K. C., Aronson, R. E., Bloom, F. R., Felizzola, J., Wolfson, M., ... McGuire, J. (2010). Latino men who have sex with men and HIV in the rural south-eastern USA: findings from ethnographic in-depth interviews. [Article]. Culture, Health \& Sexuality, 12 (7), 797-812. doi: 10.1080/13691058.2010.492432.

Rhodes, S. D., McCoy, T. P., Hergenrather, K. C., Vissman, A. T., Wolfson, M., Alonzo, J., . . . Eng, E. (2012). Prevalence Estimates of Health Risk Behaviors of Immigrant Latino Men Who Have Sex with Men. Journal of Rural Health, 28 (1), 73-83.

Semaan, S., Kay, L., Strouse, D., Sogolow, E., Mullen, P. D., Neumann, M. S., . . . Des Jarlais, D. C. (2002). A profile of U.S.-based trials of behavioral and social interventions for HIV risk reduction. Journal of Acquired Immune Deficiency Syndromes, 30 Suppl 1, S30-S50.

Stappenbeck, C. A., Hoebbel, C., \& Fals-Stewart, W. (2004). Women's indirect risks for HIV exposure: The effects of behavioral couples therapy on wives of drug-abusing men. Paper presented at the 2nd World Congress on Women's Mental Health, Washington, DC.

Sullivan, P. S., Salazar, L., Buchbinder, S., \& Sanchez, T. H. (2009). Estimating the proportion of HIV transmissions from main sex partners among men who have sex with men in five US cities. [Multicenter Study]. Aids, 23 (9), $1153-1162$. 
Tung, W.-C. (2012). HIV Among Hispanic/Latino Populations in the United States. [Article]. Home Health Care Management \& Practice, 24 (3), 153155. doi: $10.1177 / 108482231143554$.

Valdiserri, R. O., Lyter, D., Leviton, L. C., Callahan, C. M., Kingsley, L. A., \& Rinaldo, C. R. (1988). Variables influencing condom use in a cohort of gay and bisexual men. American Journal of Public Health, 78 (7), 801-805.

Wagner, G. J., Remien, R. H., \& Carballo-Dieguez, A. (1998). "Extramarital" sex: is there an increased risk for HIV transmission? A study of male couples of mixed HIV status. AIDS Education \& Prevention, 10 (3), 245-356.

Williams, J. K., Wyatt, G. E., Resell, J., Peterson, J., \& Asuan-O'Brien, A. (2004). Psychosocial Issues Among Gay- and Non-Gay-Identifying HIVSeropositive African American and Latino MSM. [Article]. Cultural Diversity \& Ethnic Minority Psychology, 10 (3), 268-286. doi: 10.1037/10999809.10.3.268

Wohl, A. R., Tejero, J., \& Frye, D. M. (2009). Factors associated with late HIV testing for Latinos diagnosed with AIDS in Los Angeles. [Article]. AIDS Care, 21 (9), 1203-1210. doi: 10.1080/09540120902729957.

Wolff, J., \& Ellis, C. (2009). A brief survey of awareness of common health conditions, access to health services, and utilization of health services in limited-English-proficiency Hispanic/Latino adults. Journal of Allied Health, 38 (2), e-43-46.

Wu, E., El-Bassel, N., Donald McVinney, L., Fontaine, Y. M., \& Hess, L. (2010). Adaptation of a Couple-Based HIV Intervention for MethamphetamineInvolved African American Men who have Sex with Men. Open AIDS J, 4, 123-131. 